\title{
Transcription Factor Assay of Peripheral Blood T Cells in Different Groups of Rheumatoid Arthritis Patients
}

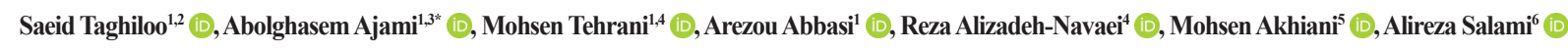

1. Department of Immunology, School of Medicine, Mazandaran University of Medical Sciences, Sari, Iran.

2. Student Research Committee, Mazandaran University of Medical Sciences, Sari, Iran.

3. Molecular and Cell-biology Research Center, Mazandaran University of Medical Sciences, Sari, Iran.

4. Gastrointestinal Cancer Research Center, Mazandaran University of Medical Sciences, Sari, Iran.

5. Department of Rheumatology, Alborz Hospital, Alborz University of Medical Sciences, Karaj, Iran.

6. Department of Biotechnology, School of Advanced Technologies in Medicine, Tehran University of Medical Sciences, Tehran, Iran.

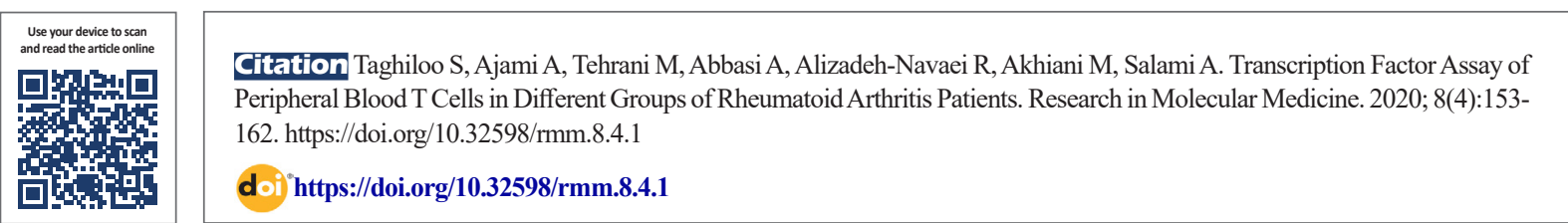

\section{(c) (1) (8)}

Article Type:

Research Paper

Article info:

Received: 29 Aug 2020

Revised: 30 Sep 2020

Accepted: 26 Oct 2020

Keywords:

Rheumatoid arthritis, T-bet, GATA3, FOXP3, RORc, Osteoarthritis

\begin{abstract}
A B S T RA C T
Background: Rheumatoid Arthritis (RA) is an autoimmune disease characterized by chronic inflammation of the joints and other tissues and organs of the body. Previous reports have demonstrated the imbalance of Thelper (Th) subsets and Treg activity in the development, progression, and remission of RA. Here, we investigated the mRNA expression of four major transcription factors T-bet (Th1), GATA (Th2), RORc (Th17), and Foxp3 (Treg) in peripheral blood of different groups of RA patients.

Materials and Methods: $\mathrm{n}$ this case-control study, 60 patients with RA, including 20 newly diagnosed, 20 under treatment, and 20 in remission, as well as 20 patients with osteoarthritis, and 20 age- and the sex-matched healthy individual were enrolled. Diagnosis and classification of patients were done according to the American College of Rheumatology criteria. The relative mRNA expression of transcription factors, including T-bet, GATA, RORc, and Foxp3, was measured using qRT-PCR.
\end{abstract}

Results: The relative expression of T-bet in RA patients was significantly increased in healthy controls $(\mathrm{P}=0.002)$, while the relative expression of Foxp3 in RA patients was significantly decreased in healthy controls $(\mathrm{P}<0.0001)$. There was no significant difference in the expression of GATA3 or RORc among RA patients, healthy controls, and osteoarthritis group.

Conclusion: The results indicate the importance of Th1 and Treg cells in RA; however, the role of Th17 cells appear to be of little importance in these patients. It seems that Th2 cells do not interfere with RA development.

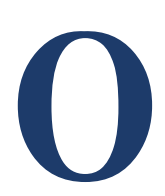

\section{Introduction}

ne of the most important systemic autoimmune disorder is Rheumatoid Arthritis (RA). It is estimated that women have been affected by RA approximately five times more than men $[1,2]$. RA inflammation mostly causes swelling and pain in small joints leading to chronic progressive joint destruction. This destruction is responsible for working disability, physical dysfunction,

\footnotetext{
* Corresponding Author:

Abolghasem Ajami, PhD.

Address: Molecular and Cell-biology Research Center, Mazandaran University of Medical Sciences, Sari, Iran.

Phone: +98 (151) 3543081

E-mail:ajami36@gmail.com
} 
and a decline in the quality of life [3]. It is presumed that in RA disease, the synovial membrane is the main affected tissue, characterized by activation of fibroblastlike synoviocytes, the formation of pannus, as well as abnormal growth, and infiltration of inflammatory cells $[4,5]$. Also, one of the most prevalent chronic situations of joint damage is Osteoarthritis (OA) that breaks down the cartilage or cushion between joints that leads to pain, swelling, and problems when moving the joint [6]. Interestingly, few leukocyte infiltrations in the synovial membrane of OA patients are seen. Furthermore, joint involvement distribution in RA patients is generally symmetrical while OA patients have an asymmetrical distribution $[7,8]$.

Nowadays, the involvement of the innate and adaptive immune system components in RA development and chronicity is determined, but the immuno-pathogenesis of RA is still not fully disclosed [9]. The two above-mentioned immune responses play a vital role in RA pathophysiology, including the generation of auto-antibodies, and $\mathrm{T}$ cell-mediated response $[10,11]$. Some auto-antibodies such as Rheumatoid Factor (RF) and anti-Cyclic Citrullinated Peptide (anti-CCP) have been recognized in approximately $50 \%$ to $80 \%$ of RA patients. They can emerge even before the appearance of arthritic symptoms $[12,13]$. T-lymphocytes and specifically T-CD4+ cells play a vital role in the progress of autoimmune disorders such as RA $[14,15]$. The T helper (Th) cells differentiate into one of the lineages of these cells, including Th1, Th2, Th17, and regulatory T cell, and they are characterized by their pattern of cytokine secretion, and transcription factors involved in the immuno-pathogenesis of RA $[16,17]$. Previous studies indicate that the incidence and development of RA in some patients result from an imbalance of Th1/Th2 and Th17/Treg cells $[18,19]$.

The main transcription factor involved in the differentiation of Th1 is T-box transcription factor (T-bet). This factor is characterized by not only enhancing the secretion of interferon (IFN)- $\gamma$ but also suppressing the development of other T helper cells [20, 21]. STAT6 is the major transcription factor of Th2 differentiation, which leads to the overexpression of GATA-3 as the main regulator [22]. Increased Th2 cytokine secretion and inhibition of Th1 differentiation are two different mechanisms of GATA3 involvement in Th2 differentiation [23]. Moreover, ROR $\gamma \mathrm{t}$ is the major transcription factor of Th17 which is transcribed by the RORc gene [21]. Accordingly, Foxp3 is not only expressed in $\mathrm{CD} 4^{+} \mathrm{CD} 25^{+}$ Treg cells but also is the main lineage-specific transcription factor involved in iTreg differentiation $[24,25]$.
However, many previous studies demonstrated the expression of these transcription factors in RA patients with contradictory findings [26-28]. Accordingly, in the current study, the mRNA expression of four main transcription factors of $\mathrm{T}$ helper subsets and Tregs, including T-bet, GATA-3, RORc, and Foxp3 in patients with RA were evaluated during different stages of the disease: newly diagnosed, under treatment, and remission. Also, non-autoimmune arthritis patients (osteoarthritis) and healthy controls were monitored and evaluated.

\section{Patients and Methods}

\section{Study patients and controls}

We enrolled the consecutive patients aged between 18 and 80 years referring to the Rheumatology Clinic of Alborz Hospital in Karaj City, Iran between January 2015 and December 2016. The patients who met the American College of Rheumatology (ACR)/European League Against Rheumatism (EULAR) 2010 criteria for RA were selected and divided into three groups: group 1 or "RA new case" $(n=20)$ were newly diagnosed RA patients with no pharmacological treatment at the time of sampling; group 2 or "RA under treatment" $(n=20)$ were those patients treated with prednisolone, methotrexate, and vitamin $\mathrm{D}$ at least for six recent months without a significant improvement in their clinical condition; and group 3 or "RA with remission" $(n=20)$ were those patients who showed a significant clinical improvement of the disease (based on the criteria of ACR, 2010) over the past 6 months while they only received minimal treatment. Furthermore, 20 patients who fulfilled the ACR classification criteria for OA were selected as group 4, and finally, 20 healthy volunteers with no history of any rheumatologic or other chronic inflammatory diseases were selected as the healthy control group. Written informed consent was taken from all participants and the study was approved by the Ethics Committee of Mazandaran University of Medical Sciences. Medical routine laboratory tests for RA patients such as Erythrocyte Sedimentation Rate (ESR), C-Reactive Protein (CRP), and RF were performed and collected by the clinical laboratory of Alborz Hospital. The major clinical and laboratory characteristics of patients with RA or osteoarthritis and healthy controls are summarized in Table 1.

\section{RNA isolation and cDNA synthesis}

The whole blood specimens were collected, and total RNA was extracted from specimens using GENEzol ${ }^{\mathrm{TM}}$ TriRNA Pure Kit (Geneaid, USA) based on the manufacturer's protocol. First, the quality of extracted RNA was 
evaluated by nano-spectrophotometer (Thermo Fisher Scientific Inc., USA) and agarose gel electrophoresis. Then, DNA was removed by deoxyribonuclease1 (Invitrogen, USA) enzyme. The synthesis of complementary DNA (cDNA) was done using the Thermo Scientific RevertAid first-strand cDNA synthesis kit (Thermo Scientific, Massachusetts, USA) based on the manufacturer's instructions.

\section{Quantitative reverse-transcriptase PCR}

To measure the four main transcription factors expression, quantitative reverse-transcriptase (qRT)-PCR was carried out using SYBR Green/ROX qPCR Master Mix (Thermo Scientific, USA) reagent in a real-time PCR with Light Cycler $^{\circledR}$ system (Roche, Germany) using the following specific primers. The primer sequences are shown in Table 2. The primer efficiencies were defined as $98.7 \%, 101 \%, 104.1 \%, 102 \%$, and $99.4 \%$ for $T$-bet, GATA-3, Foxp-3, RORc, and GAPDH, respectively. The PCR reactions were amplified at $95^{\circ} \mathrm{C}$ for initial denaturation followed by 40 cycles at $95^{\circ} \mathrm{C}$ for 15 seconds, $57^{\circ} \mathrm{C}$ (T-bet), $58^{\circ} \mathrm{C}$ (GATA-3), $59^{\circ} \mathrm{C}$ (Foxp-3), $60^{\circ} \mathrm{C}$ (RORc) and $60^{\circ} \mathrm{C}(\mathrm{GAPDH})$ for 30 seconds, and extension at $72^{\circ} \mathrm{C}$ for 30 seconds. The PCR amplicon sizes were 128 bp, 88 bp, 163 bp, 101 bp, and 126 bp for T-bet, GATA-3, Foxp-3, RORc, and GAPDH, respectively. The relative expression level of these genes was carried out with $2^{-\Delta \mathrm{Ct}}$ value using $G A P D H$ as an internal housekeeping gene.

\section{Statistical analysis}

For the statistical study, Graph Pad Prism statistical software, version 5.01 (Graph Pad, San Diego, CA, USA) was used. The data normality was evaluated by the Kolmogorov-Smirnov test. Mann-Whitney U test was considered to compare the mean differences between the two groups. Also, for comparing quantitative differences of transcription factors expression among the groups, the Kruskal-Wallis test was used. Spearman's rank correlation analysis was used to calculate the correlation coefficients. Data are presented as median (interquartile range) and $\mathrm{P}$ values less than 0.05 were considered significant.

\section{Results}

Up-regulation of T-bet mRNA expression in newly diagnosed RA patients

To evaluate the gene expression profile of an important transcription factor of Th1 cells, the relative mRNA expression of T-bet was examined in patients with RA using the qRT-PCR method. Also, GAPDH was amplified in all the experiments as an internal control. Our finding showed that the relative expression of T-bet was significantly different in five groups ( $\mathrm{P}=0.002$, Figure 1). T-bet was highly upregulated in newly diagnosed RA patients compared to normal subjects ( $\mathrm{P}=0.005$, Figure $1 \mathrm{~A})$. It is interesting to note that, T-bet mRNA level measured in newly diagnosed RA patients was four times higher than that of healthy controls (Figure 1B). Also, the mRNA expression of T-bet in the treatment groups, the remission groups, and the osteoarthritis groups was significantly higher than that in the normal subjects $(\mathrm{P}=0.07, \mathrm{P}<0.0001$, $\mathrm{P}=0.006$, respectively, Figure $1 \mathrm{~A})$. In this regard, T-bet mRNA level measured in the treatment groups, the remission groups, and the osteoarthritis groups were nearly two times higher than that of normal subjects (Figure 1B).

\section{GATA-3 was not expressed in RA new cases}

The relative mRNA expression of GATA-3 in all groups did not show a statistically significant difference $(\mathrm{P}=0.3$, Figure 2A). As shown in Figure 2B, the fold increase of mRNA expression of GATA-3 was calculated. Also, the difference between all groups was not statistically significant.

\section{Down-regulation of Foxp3 in RA patients}

Foxp 3 mRNA expression was evaluated using qRTPCR in five groups. As shown in Figure 3, the relative expression of Foxp3 was significantly different among the five study groups $(\mathrm{P}<0.0001)$. The expression of Foxp3 was significantly lower in newly diagnosed RA patients, the treatment groups, and the remission groups compared to that in the healthy controls $(\mathrm{P}=0.002$, $\mathrm{P}<0.0001$, and $\mathrm{P}<0.0001$, respectively, Figure $3 \mathrm{~A} \& \mathrm{~B}$ ). Similarly, Foxp 3 expression was lower in the osteoarthritis groups in comparison with healthy controls although the difference was not statically significant $(\mathrm{P}=0.09$, Figure 3). Notably, the relative expression of Foxp 3 was significantly decreased in the treatment groups and the remission groups compared to the newly diagnosed RA patients ( $\mathrm{P}<0.0001, \mathrm{P}=0.01$, respectively, Figure 3$)$. Besides, to explore Foxp 3 expression in non-autoimmune arthritis, Foxp 3 mRNA expression in osteoarthritis was also analyzed. The relative expression of Foxp 3 was significantly lower in the treatment groups and remission groups of RA compared to the osteoarthritis groups $(\mathrm{P}<0.0001, \mathrm{P}=0.03$, respectively, Figure 3$)$.

RORc expression was not statistically different in RA new case

$R O R c$ mRNA expression in the whole blood of five study groups was evaluated using qRT-PCR. There was 
Table 1. Major clinical and laboratory characteristics of RA patients, osteoarthritis patients, and healthy controls

\begin{tabular}{|c|c|c|c|c|c|c|}
\hline \multirow{2}{*}{\multicolumn{2}{|c|}{ Variabels }} & \multicolumn{5}{|c|}{ Mean $\pm S D / N o .(\%)$} \\
\hline & & RA-New Cases ( $n=20)$ & RA-Treatment ( $n=20)$ & Remission $(n=20)$ & $\begin{array}{l}\text { Osteoarthritis } \\
(n=20)\end{array}$ & Control $(n=20)$ \\
\hline \multicolumn{2}{|c|}{ Age (y) } & $49.56 \pm 11$ & $54.65 \pm 12.6$ & $48.35 \pm 11.8$ & $52.8 \pm 7$ & $45 \pm 10$ \\
\hline Gender & $\begin{array}{l}\text { Male } \\
\text { Female }\end{array}$ & $\begin{array}{c}6(30) \\
14(70)\end{array}$ & $\begin{array}{c}6(30) \\
14(70)\end{array}$ & $\begin{array}{c}2(10) \\
18(90)\end{array}$ & $\begin{array}{c}0(0) \\
20(100)\end{array}$ & $\begin{array}{c}6(30) \\
14(70)\end{array}$ \\
\hline \multicolumn{2}{|c|}{ ESR, mm/hour } & $37.3 \pm 6.8$ & $30.3 \pm 13.7$ & $9.8 \pm 4.3$ & $14.3 \pm 2.4$ & - \\
\hline CRP & $\begin{array}{l}\text { Positive } \\
\text { Negative }\end{array}$ & $\begin{array}{c}18(100) \\
0(0)\end{array}$ & $\begin{array}{l}13(65) \\
7(35)\end{array}$ & $\begin{array}{c}2(10) \\
18(90)\end{array}$ & $\begin{array}{c}0(0) \\
20(100)\end{array}$ & $\begin{array}{l}- \\
-\end{array}$ \\
\hline $\mathrm{RF}$ & $\begin{array}{l}\text { Positive } \\
\text { Negative }\end{array}$ & $\begin{array}{c}18(100) \\
0(0)\end{array}$ & $\begin{array}{l}16(80) \\
4(20)\end{array}$ & $\begin{array}{c}0(0) \\
20(100)\end{array}$ & $\begin{array}{c}0(0) \\
20(100)\end{array}$ & - \\
\hline \multicolumn{2}{|c|}{ Anti-CCP, IU/mL } & $127.1 \pm 47.4$ & $91.6 \pm 52.5$ & $7.9 \pm 2.6$ & $2.15 \pm 1.2$ & - \\
\hline
\end{tabular}

RA: Rheumatoid Arthritis; ESR: Erythrocyte Sedimentation Rate; CRP: C-Reactive Protein; RF: Rheumatoid Factor; anti-CCP: anti-Cyclic Citrullinated Peptide

Table 2. Primer sequences and amplicon lengths for the specific qRT-PCR of T-bet, GATA3, Foxp3, RORc, and GAPDH

\begin{tabular}{|c|c|c|}
\hline Target & Primer Sequence & Amplicon \\
\hline $\begin{array}{c}\text { T-bet } \\
\text { Forward } \\
\text { Reverse }\end{array}$ & $\begin{array}{l}5^{\prime}-\text { TGCATATCGTTGAGGTGAACG - } 3^{\prime} \\
5^{\prime} \text { - CTGAGTAATCTCGGCATTCTG -3' }\end{array}$ & $128 \mathrm{bp}$ \\
\hline $\begin{array}{l}\text { GATA-3 } \\
\text { Forward } \\
\text { Reverse }\end{array}$ & $\begin{array}{l}\text { 5'- GGCTCTACTACAAGCTTCACAAT -3' } \\
5^{\prime} \text { - TTGCTAGACATTTTTCGGTTCTG - } 3^{\prime}\end{array}$ & 88 bp \\
\hline $\begin{array}{l}\text { Foxp3 } \\
\text { Forward } \\
\text { Reverse }\end{array}$ & $\begin{array}{l}\text { 5'- CAGCACATTCCCAGAGTTCC -3' } \\
\text { 5'- GGCAAACATGCGTGTGAACC - } 3^{\prime}\end{array}$ & $163 \mathrm{bp}$ \\
\hline $\begin{array}{l}\text { RORC } \\
\text { Forward } \\
\text { Reverse }\end{array}$ & $\begin{array}{l}\text { 5'- ACCGATGTGGACTTCGTTTTG -3' } \\
\text { 5'- CGGTGTGCTGCGGAAACT -3' }\end{array}$ & $101 \mathrm{bp}$ \\
\hline $\begin{array}{l}\text { GAPDH } \\
\text { Forward } \\
\text { Reverse }\end{array}$ & $\begin{array}{l}\text { 5'- AAGCTCATTTCCTGGTATGACG-3' } \\
\text { 5'- TCTTCCTCTTGTGCTCTTGCTGG -3' }\end{array}$ & $126 \mathrm{bp}$ \\
\hline
\end{tabular}

grmm

no significant difference in RORc mRNA expression between the five groups. Similarly, it must be indicated that the calculated fold increases of mRNA expression of $R O R c$ were not statistically significant between all groups $(\mathrm{P}=0.2$, Figure 4$)$.

Anti-CCP was positively correlated with T-bet and $R O R c$ expression, and negatively correlated with GATA3 and Foxp 3 expression in RA patients under treatment.

To find out any correlations between the expressions of T-bet, GATA-3, Foxp3, and RORc with the results of serological tests such as the levels of anti-CCP, RF, and ESR in RA patients under treatment were analyzed. As shown in Figure 5A, T-bet mRNA expression was significantly correlated with the levels of anti-CCP $(r=0.443$, $\mathrm{P}=0.05$, Figure $5 \mathrm{~A}$ ). Moreover, no significant correlations were observed between RORc mRNA expression and the levels of anti-CCP $(\mathrm{r}=0.383, \mathrm{P}=0.1$, Figure $5 \mathrm{~B})$.
Inversely, the GATA-3 and Foxp3 mRNA expressions were negatively correlated with the levels of anti-CCP in RA patients under treatment, but not significantly different $(\mathrm{r}=-0.092, \mathrm{P}=0.7$ and $\mathrm{r}=-0.173, \mathrm{P}=0.4$, respectively, Figure 5C\&D). However, our results indicated that the expression of T-bet, GATA-3, Foxp3, and RORc were not significantly correlated with the levels of anti-CCP in newly diagnosed RA, remission RA patients, and patients with osteoarthritis; also the expression of these transcription factors was not significantly correlated with the levels of RF and ESR in RA patients under treatment, newly diagnosed RA, remission RA patients, and patients with osteoarthritis (not depicted).

\section{Discussion}

The appearance and progression of autoimmune disease, due to the disturbance of $\mathrm{CD}^{+}{ }^{+} \mathrm{T}$ cells has been illustrated [29]. Therefore, numerous studies have shown 

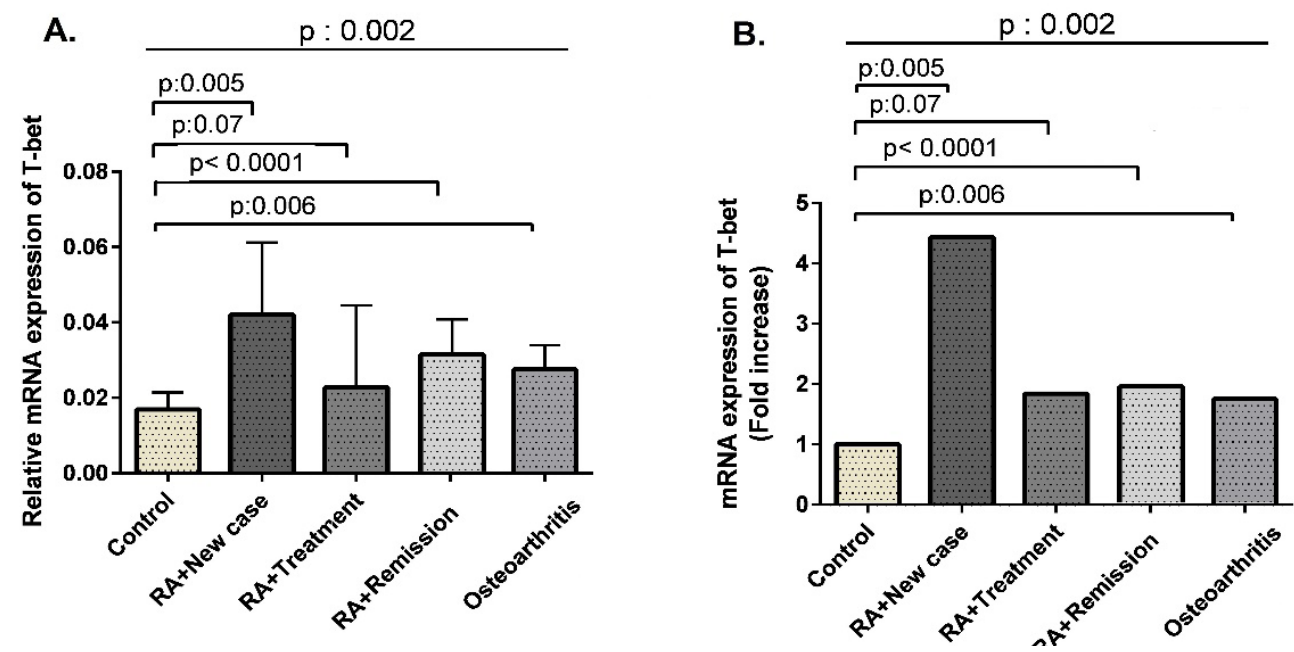

Figure 1. The mRNA expression of T-bet in RA patients, osteoarthritis, and healthy controls A: The relative mRNA expression of T-bet; B: Fold increase

The results are presented as Median \pm Interquartile Range (IQR).
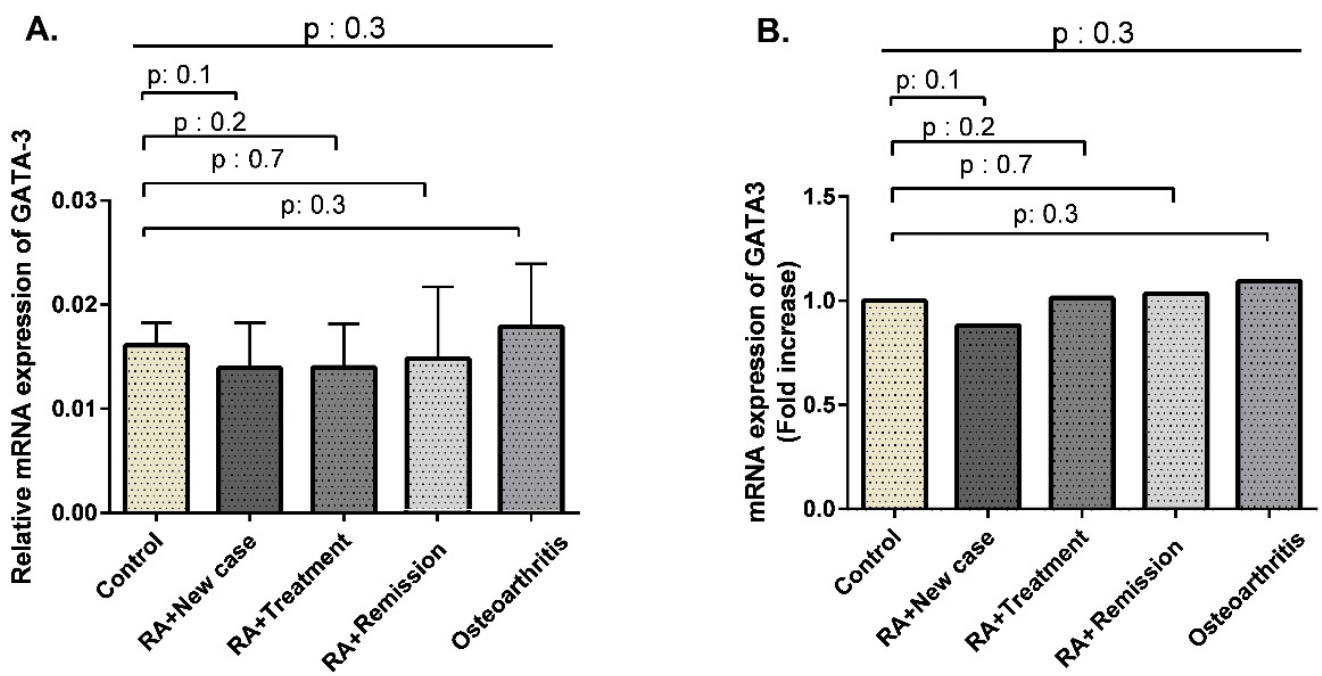

Figure 2. The mRNA expression of GATA-3 in RA patients, osteoarthritis, and healthy controls A: The relative mRNA expression of GATA-3; B: Fold increase;

The results are presented as Median \pm Interquartile Range (IQR).

that the imbalance between $\mathrm{CD}^{+} \mathrm{T}$ cell subsets containing Th1, Th2, Th17, and Treg cells play a critical role in the pathogenesis of RA. The purpose of the current study was to investigate the correlation of the transcription factors of CD4+ T cell subsets in five groups of subjects, including patients with newly diagnosed RA, RA under treatment, RA in remission, patients with osteoarthritis, and healthy controls.

Firstly, our findings showed that the expression of T-bet is upregulated in RA patients when compared to healthy controls, whenever the expression of Foxp3 is down- regulated in RA patients. Additionally, T-bet mRNA expression was meaningfully correlated with anti-CCP levels. Interestingly, the expression levels of GATA-3 and $R O R c$ were not significantly different among the five study groups. Moreover, no correlation exists between the levels of anti-CCP and RORc expression. In RA patients under treatment, the expression of GATA-3 and Foxp3 were negatively correlated with the levels of anti-CCP.

Recent studies demonstrated that the imbalance of Th1/ Th2 and Th17/Treg cells may cause the appearance and 

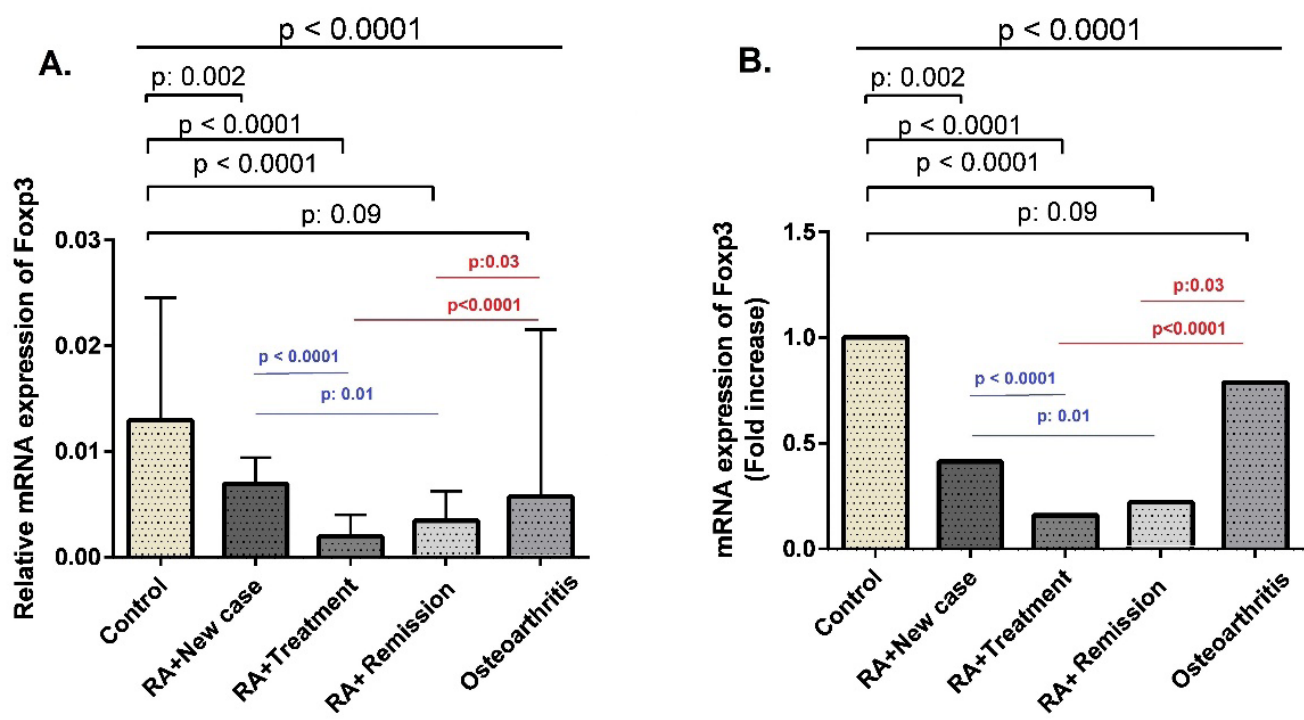

Figure 3. The mRNA expression of Foxp3 in RA patients, osteoarthritis, and healthy controls

A: The relative mRNA expression of Foxp3; B: Fold increase

The results are presented as Median \pm Interquartile Range (IQR).
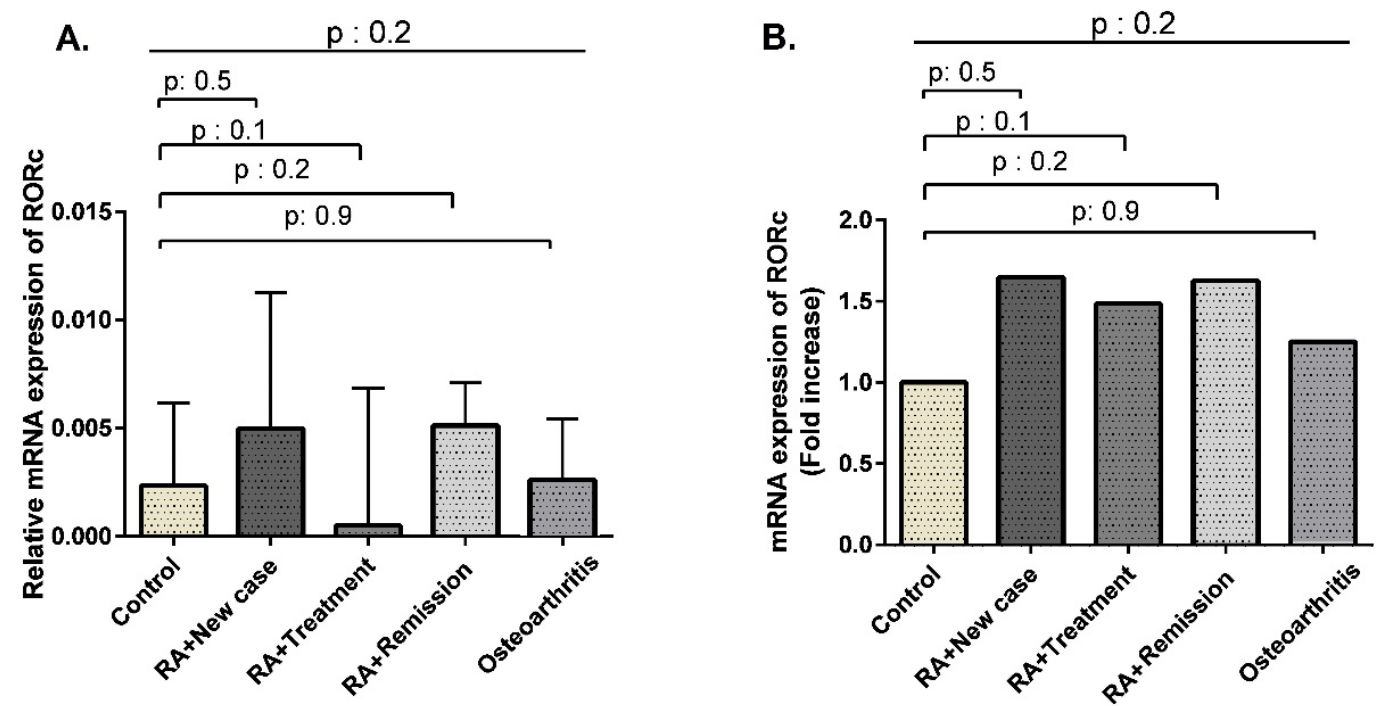

Figure 4. The mRNA expression of RORc in RA patients, osteoarthritis, and healthy controls

A: The relative mRNA expression of RORc; B: Fold increase;

The results are presented as Median \pm Interquartile Range (IQR).

progression of RA [30]. Therefore, it is of utmost importance to restore this balance in RA [19]. Convincing evidence supported that RA was a Th1 cell-driven chronic inflammatory condition [31]. Th1/Th2 imbalance originated from an increase in inflammatory cytokines leads to an accompanying decrease in anti-inflammatory cytokines [32]. Our results disclosed that the expression of T-bet, as the main transcription factor for the Th1 subset, was notably elevated in RA patients. The expression of T-bet seems to be increased at the beginning of inflam- mation, whereas during treatment gradually reduces the expression of this transcription factor by blocking cellular immunity with immunosuppressive drugs. As it is mentioned above, since the expression of GATA-3 that is the key transcription factor for the Th2 subset did not exhibit notable differences among the five groups of the study subjects, humoral immunity in RA patients is not as consequential as cellular immunity. Our findings are in line with Chen et al. study results. The report demonstrated that the frequency of Th1 and Th2 cells were 
A.

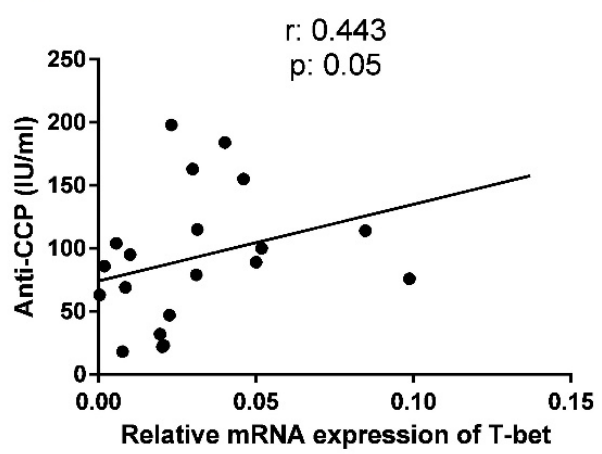

C.

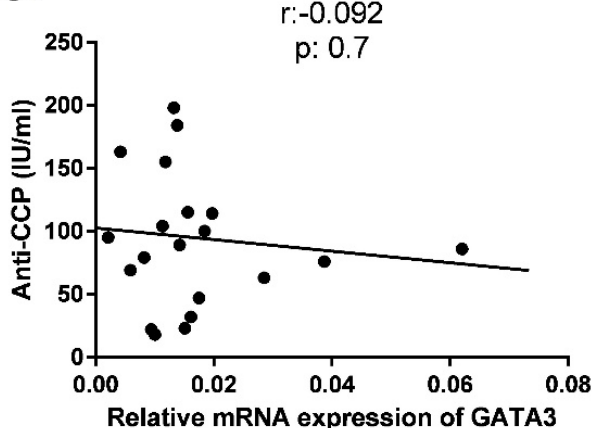

B.

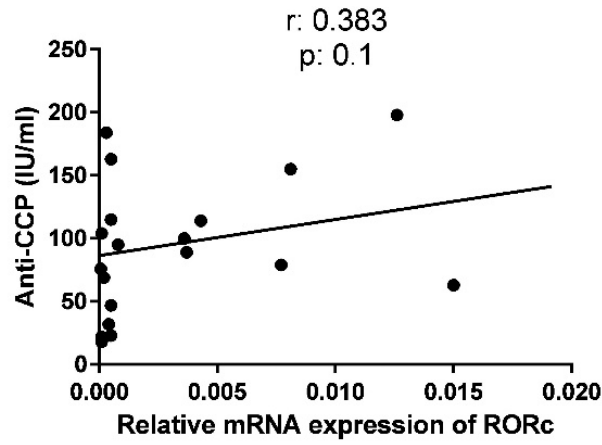

D.

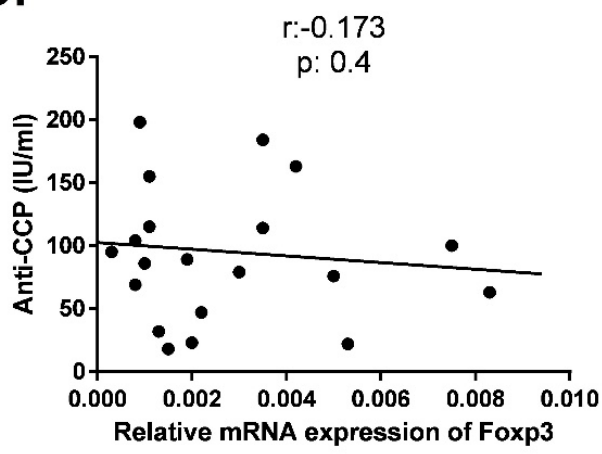

Brmm

Figure 5. Correlation analysis of T-bet, GATA-3, Foxp-3, and RORc mRNA expression with the levels of anti-CCP in RA patients under treatment

A: The levels of anti-CCP was significantly associated with the expression of $T$-bet $(\mathrm{r}=0.443, \mathrm{P}=0.05)$; $\mathrm{B}$ : The expression of $R O R c$ $(\mathrm{r}=0.383, \mathrm{P}=0.1)$; $\mathrm{C}$ : The expression of GATA-3 ( $\mathrm{r}=-0.092, \mathrm{P}=0.7)$; and $\mathrm{D}$ : Expression of Foxp3 of RA patients under treatment $(\mathrm{r}=-0.173, \mathrm{P}=0.4)$. Statistical comparisons were done by the Spearman's rank correlation test.

higher and lower, respectively in RA patients [32]. Although Th1/Th2 imbalance can reasonably clarify the pathogenesis of RA, there are still several indisputable facts [26].

The identification of Treg cells and Th17 cells have induced vast lines of research into the potential roles of these cells in controlling RA [28]. The results of the present study demonstrated the significantly lower relative mRNA expression of Foxp3, as the main transcription factor for Tregs, in RA patients compared to healthy controls. It should be also indicated that the expression of $R O R c$, as the main transcription factor for the Th17 subset, did not show striking differences between the five groups of the study subjects. The involvement of Treg cells is shown in suppressing the activity of the immune system and at the same time blockade of the activity of Th1 and Th2 cells. Moreover, it can inhibit humoral and cellular immune responses leading to autoimmune prevention. Contrary to our results, previous studies report that the frequency of Th17 cells is increased in all stages of RA patients compared with that in the healthy controls [33]. Furthermore, previous reports in patients with RA show that Treg cells are elevated not only in the frequency but also in the suppressive activity $[34,35]$. While the exact mechanism is unclear, Treg cells are suggested to have an immune inhibition effect on the differentiation of Th1 7 cells. The imbalance of Th1/Th2 and Th17/Treg has been described in the appearance and progression of some autoimmune diseases such as RA [26]. Th1 and Th17 cells play a pro-inflammatory role and have been involved in several inflammatory situations in humans [36]; however, an anti-inflammatory role is ascribed to Th2 and Treg cells [32]. Besides, with increasing the severity of the disease, the expression of T-bet exceeds the expression of Foxp3, and the severity of inflammation and disease activity relies on the increase in T-bet/Foxp3 proportion [37]. Both Th1 and Th17 cells are responsible for $\mathrm{CD}^{+} \mathrm{T}$ cell-mediated inflammatory disease, but it is obvious that in the presence of Th1 responses, Th17 
differentiation is inhibited due to IFN- $\gamma$ production. Our result indicate that in new cases, Th17 subsets is prominent to other subsets, but as the disease becomes chronic, Th17 cells shift to Th1 cells. In other words, antagonists treatment that block the development or function of Th17 cells such as anti-IL-17 are in clinical trials for several inflammatory diseases and are approved for the treatment of psoriasis. However, these antagonists are not effective in inflammatory bowel disease and perhaps in rheumatoid arthritis as well, so the role of Th17 cells in these diseases is uncertain.

As it was mentioned, the majority of studies have compared the expression of genes between patients with the healthy group while in this study, the patients were analyzed for the first time in three stages of rheumatoid arthritis, and were compared with patients with osteoarthritis and healthy controls.

\section{Conclusions}

In summary, the study results indicate that alterations in the expression of T-bet and Foxp3 were greater than the expression of GATA-3 and RORc. In other words, Th1 and Treg cells were more important than Th2 and Th17 cells in RA pathogenesis. As a result, a better understanding of the biological mechanisms involved in this process may lead to more effective therapies for RA.

\section{Ethical Considerations}

\section{Compliance with ethical guidelines}

All procedures performed according to the ethical standards of the institutional and or national research committee as well as the 1964 Helsinki Declaration and its later amendments. This study was approved by the Ethics Committee of Mazandaran University of Medical Sciences (IR.MAZUMS.REC.1393.1335).

\section{Funding}

This study was supported by Mazandaran University of This study was financially supported by Mazandaran University of Medical Sciences (Grant No.: IR.MAZUMS.REC. 1393. 1335).

\section{Authors' contributions}

Conceptualization, Supervision, and Project administration: Abolghasem Ajami; Methodology: Mohsen Tehrani, Alireza Salami, and Mohsen Akhiani; Investigation: Saeid Taghiloo and Arezou Abbasi; Software and formal analysis: Reza Alizadeh-Navaei; Data curation and Writing-original draft preparation: Saeid Taghiloo; Writing-review and editing: Mohsen Tehrani; Funding acquisition and Resources: Abolghasem Ajami.

\section{Conflict of interest}

The authors declared no conflict of interest.

\section{Acknowledgements}

The authors thank the patients and their families for their support, cooperation, and patience. We would like to thank the staff of the departments associated with care and management of the patients. This study was financially supported by Mazandaran University of Medical Sciences.

\section{References}

[1] Fabris M, De Vita S, Blasone N, Visentini D, Pezzarini E, Pontarini E, et al. Serum levels of anti-CCP antibodies, anti$\mathrm{MCV}$ antibodies and RF IgA in the follow-up of patients with rheumatoid arthritis treated with rituximab. Autoimmun Highl. 2010; 1(2):87-94. [DOI:10.1007/s13317-010-00135] [PMID] [PMCID]

[2] Förger F, Villiger PM. Immunological adaptations in pregnancy that modulate rheumatoid arthritis disease activity. Nat Rev Rheumatol. 2020:1-10. [DOI:10.1038/s41584-0200394-4] [PMID]

[3] Furst DE, Emery P. Rheumatoid arthritis pathophysiology: Update on emerging cytokine and cytokine-associated cell targets. Rheumatology. 2014; 53(9):1560-9. [DOI:10.1093/ rheumatology/ket414] [PMID] [PMCID]

[4] Firestein GS. Evolving concepts of rheumatoid arthritis Nature. 2003; 423(6937):356-61. [DOI:10.1038/nature01661] [PMID]

[5] Chang CM, Hsu YW, Wong HSC, Wei JCC, Liu X, Liao HT, et al. Characterization of T-Cell receptor repertoire in patients with rheumatoid arthritis receiving biologic therapies. Dis Markers. 2019:2364943. [DOI:10.1155/2019/2364943] [PMID] [PMCID]

[6] Watt FE. Osteoarthritis biomarkers: year in review. Osteoarthritis Cartilage. 2018; 26(3):312-8. [DOI:10.1016/j. joca.2017.10.016] [PMID]

[7] Müller-Ladner U, Pap T, Gay RE, Neidhart M, Gay S. Mechanisms of disease: The molecular and cellular basis of joint destruction in rheumatoid arthritis. Nat Clin Pract Rheumatology. 2005; 1(2):102-10. [DOI:10.1038/ncprheum0047] [PMID]

[8] Majithia V, Geraci SA. Rheumatoid arthritis: Diagnosis and management. Am J Med. 2007;120(11):936-9. [DOI:10.1016/j. amjmed.2007.04.005] [PMID] 
[9] Klareskog L, Catrina AI, Paget S. Rheumatoid arthritis. Lancet (London, England). 2009; 373(9664):659-72. [DOI:10.1016/S0140-6736(09)60008-8]

[10] Moschovakis GL, Bubke A, Friedrichsen M, Falk CS, Feederle R, Förster R. T cell specific Cxcr5 deficiency prevents rheumatoid arthritis. Sci Rep. 2017; 7(1):8933. [DOI:10.1038/ s41598-017-08935-6] [PMID] [PMCID]

[11] Wehr P, Purvis H, Law SC, Thomas R. Dendritic cells, T cells and their interaction in rheumatoid arthritis. J Clin Exp Immunol. 2019; 196(1):12-27. [DOI:10.1111/cei.13256] [PMID] [PMCID]

[12] Majka DS, Deane KD, Parrish LA, Lazar AA, Baron AE, Walker CW, et al. Duration of preclinical rheumatoid arthritis-related autoantibody positivity increases in subjects with older age at time of disease diagnosis. Ann Rheum Dis. 2008; 67(6):801-7. [DOI:10.1136/ard.2007.076679] [PMID] [PMCID]

[13] Nielen MM, van Schaardenburg D, Reesink HW, van de Stadt RJ, van der Horst-Bruinsma IE, de Koning MH, et al. Specific autoantibodies precede the symptoms of rheumatoid arthritis: a study of serial measurements in blood donors. Arthritis Rheum. 2004; 50(2):380-6. [DOI:10.1002/ art.20018] [PMID]

[14] Zhou H, Hu B, Zhaopeng Z, Liu J, Zhong Q, Fan Y, et al. Elevated circulating $\mathrm{T}$ cell subsets and cytokines expression in patients with rheumatoid arthritis. Clin Rheumatol. 2019; 38(7):1831-9. [DOI:10.1007/s10067-019-04465-w] [PMID]

[15] Weyand CM, Goronzy JJ. Immunometabolism in the development of rheumatoid arthritis. Immunol Rev. 2020; 294(1):177-87. [DOI:10.1111/imr.12838] [PMID]

[16] Toh M-L, Miossec P. The role of T cells in rheumatoid arthritis: New subsets and new targets. Curr Opin Rheumatol. 2007; 19(3):284-8. [DOI:10.1097/BOR.0b013e32805e87e0] [PMID]

[17] Alunno A, Bartoloni E, Nocentini G, Bistoni O, Ronchetti S, Petrillo MG, et al. Role of regulatory T cells in rheumatoid arthritis: Facts and hypothesis. Autoimmun Highl. 2010; 1(1):45. [DOI:10.1007/s13317-010-0008-2] [PMID] [PMCID]

[18] Afzali B, Lombardi G, Lechler R, Lord G. The role of T helper 17 (Th17) and regulatory $\mathrm{T}$ cells (Treg) in human organ transplantation and autoimmune disease. Clin Exp Immunol. 2007; 148(1):32-46. [DOI:10.1111/j.13652249.2007.03356.x] [PMID] [PMCID]

[19] Chen J, Yang J, Qiao Y, Li X. Understanding the regulatory roles of natural killer $\mathrm{T}$ cells in rheumatoid arthritis: T helper cell differentiation dependent or independent? Scand J Immunol. 2016; 84(4):197-203.[DOI:10.1111/sji.12460] [PMID]

[20] Lugo-Villarino G, Maldonado-López R, Possemato R, Peñaranda C, Glimcher LH. T-bet is required for optimal production of IFN- $\gamma$ and antigen-specific T cell activation by dendritic cells. Proc Natl Acad Sci. 2003; 100(13):7749-54. [DOI:10.1073/pnas.1332767100] [PMID] [PMCID]

[21] Lazarevic V, Chen X, Shim J-H, Hwang E-S, Jang E, Bolm AN, et al. T-bet represses TH17 differentiation by preventing Runx1-mediated activation of the gene encoding ROR [gamma] t. Nat Immunol. 2011; 12(1):96-104. [DOI:10.1038/ ni.1969] [PMID] [PMCID]
[22] Glimcher LH, Murphy KM. Lineage commitment in the immune system: The T helper lymphocyte grows up. Genes Dev. 2000; 14(14):1693-711. http://genesdev.cshlp.org/content/14/14/1693.short

[23] Zhu J, Yamane H, Cote-Sierra J, Guo L, Paul WE. GATA3 promotes Th2 responses through three different mechanisms: Induction of Th2 cytokine production, selective growth of Th2 cells and inhibition of Th1 cell-specific factors. Cell Res. 2006; 16(1):3-10. [DOI:10.1038/sj.cr.7310002] [PMID]

[24] Fontenot JD, Gavin MA, Rudensky AY. Foxp3 programs the development and function of $\mathrm{CD} 4^{+} \mathrm{CD} 25^{+}$regulatory T cells. Nat Immunol. 2003; 4(4):330-6. [DOI:10.1038/ni904] [PMID]

[25] Zheng Y. A rogue foxp3 mutant undermines treg cell function. Immunity. 2017; 47(2):211-4. [DOI:10.1016/j.immuni.2017.07.024] [PMID]

[26] Boissier MC, Assier E, Falgarone G, Bessis N. Shifting the imbalance from Th1/Th2 to Th17/treg: The changing rheumatoid arthritis paradigm. Joint, Bone, Spine: Revue Du Rumatisme. 2008; 75(4):373-5. [DOI:10.1016/j.jbspin.2008.04.005] [PMID]

[27] Wang W, Shao S, Jiao Z, Guo M, Xu H, Wang S. The Th17/ Treg imbalance and cytokine environment in peripheral blood of patients with rheumatoid arthritis. Rheumatol Int 2012; 32(4):887-93. [DOI:10.1007/s00296-010-1710-0] [PMID]

[28] Al-Zifzaf DS, El Bakry SA, Mamdouh R, Shawarby LA, Ghaffar AYA, Amer HA, et al. FoxP3 ${ }^{+} \mathrm{T}$ regulatory cells in Rheumatoid arthritis and the imbalance of the Treg/TH17 cytokine axis. Egypt Rheumatologist. 2015; 37(1):7-15. [DOI:10.1016/j.ejr.2014.06.004]

[29] Luckheeram RV, Zhou R, Verma AD, Xia B. CD4(+)T cells: differentiation and functions. Clin Dev Immunol. 2012; 2012:925135. [DOI:10.1155/2012/925135] [PMID] [PMCID]

[30] Lina C, Conghua W, Nan L, Ping Z. Combined treatment of etanercept and MTX reverses Th1/Th2, Th17/Treg imbalance in patients with rheumatoid arthritis. J Clin Immunol. 2011; 31(4):596-605. [DOI:10.1007/s10875-011-9542-6] [PMID]

[31] Barksby HE, Lea SR, Preshaw PM, Taylor JJ. The expanding family of interleukin-1 cytokines and their role in destructive inflammatory disorders. Clin Exp Immunol. 2007; 149(2):217-25. [DOI:10.1111/j.1365-2249.2007.03441.x] [PMID] [PMCID]

[32] Chen J, Li J, Gao H, Wang C, Luo J, Lv Z, et al. Comprehensive evaluation of different T-helper cell subsets differentiation and function in rheumatoid arthritis. J Biomed Biotechnol. 2012; 2012:535361. [DOI:10.1155/2012/535361] [PMID] [PMCID]

[33] Chabaud M, Durand JM, Buchs N, Fossiez F, Page G, Frappart L, et al. Human interleukin-17: AT cell-derived proinflammatory cytokine produced by the rheumatoid synovium. Arthritis Rheumatol. 1999; 42(5):963-70. [DOI:10.1002/1529-0131(199905)42:53.0.CO;2-E]

[34] Han GM, O'Neil-Andersen NJ, Zurier RB, Lawrence DA. $\mathrm{CD} 4{ }^{+} \mathrm{CD} 25$ high $\mathrm{T}$ cell numbers are enriched in the peripheral blood of patients with rheumatoid arthritis. Cell Immunol. 2008; 253(1):92-101. [DOI:10.1016/j.cellimm.2008.05.007] [PMID] [PMCID] 
[35] van Amelsfort JM, Jacobs KM, Bijlsma JW, Lafeber FP, Taams LS. $\mathrm{CD}^{+}{ }^{+} \mathrm{CD} 25^{+}$regulatory $\mathrm{T}$ cells in rheumatoid arthritis: differences in the presence, phenotype, and function between peripheral blood and synovial fluid. Arthritis Rheumatol. 2004; 50(9):2775-85. [DOI:10.1002/art.20499] [PMID]

[36] Dardalhon V, Korn T, Kuchroo VK, Anderson AC. Role of Th1 and Th17 cells in organ-specific autoimmunity. J Autoimmun. 2008; 31(3):252-6. [DOI:10.1016/j.jaut.2008.04.017] [PMID] [PMCID]

[37] Behrens F, Himsel A, Rehart S, Stanczyk J, Beutel B, Zimmermann SY, et al. Imbalance in distribution of functional autologous regulatory $\mathrm{T}$ cells in rheumatoid arthritis. Ann Rheum Dis. 2007; 66(9):1151-6. [DOI:10.1136/ ard.2006.068320] [PMID] [PMCID] 